\title{
O Papel do Controller no Planejamento Estratégico de uma Empresa
}

\author{
Renata Louise Alves ${ }^{1}$; Maria Erilúcia Cruz Macedo ${ }^{2}$
}

\begin{abstract}
Resumo: O presente trabalho tem como tema "O papel do Controller no planejamento estratégico de uma empresa", abordando a controladoria como a evolução da contabilidade, voltado para disponibilizar informações de controle, evidenciando os custos, receitas e despesas das demonstrações, para tomada de decisão dos gestores. Neste contexto intuito deste trabalho é evidenciar a importância do Controller e suas técnicas, e como elas afetam positivamente no planejamento estratégico de uma empresa, bem como, conceituar controladoria; identificar o perfil do Controller; e apresentar as funções e atribuições que cabem a Controladoria e ao Controller. Para a realização deste trabalho foi utilizada a pesquisa bibliográfica, descritiva e qualitativa, tendo como instrumento o referencial teórico já produzido em livros, revistas, artigos e demais publicações. Por fim, as pesquisas mostram a existência de um novo perfil da controladoria como ferramenta chave na orientação dos gestores, garantindo informações tempestivas e relevantes no processo de tomada de decisões.
\end{abstract}

Palavras chave: Controladoria. Controller. Planejamento Estratégico.

\section{The Role of the Controller in a Company's Strategic Planning}

\begin{abstract}
This paper has the theme "The Role of the Controller in a Company's Strategic Planning", approaching control as the evolution of accounting, aimed at providing control information, showing the costs, revenues and expenses of the decision of the managers. In this context, the purpose of this paper is to highlight the importance of the Controller and its techniques, and how they affect positively in the strategic planning of a company, as well as, conceptualize control; identify the Controller profile; and present the functions and attributions that fit Controllership and Controller. For the accomplishment of this work the bibliographical research, descriptive and qualitative was used, having as instrument the theoretical reference already produced in books, magazines, articles and other publications. Finally, the surveys show the existence of a new controller profile as a key tool in guiding managers, ensuring timely and relevant information in the decision-making process.
\end{abstract}

Keywords: Controllership. Controller. Strategic planning.

\section{Introdução}

No cenário atual das empresas, pode-se perceber que a função da contabilidade deixou de se restringir apenas a documentação e atividades de escrituração e registros contábeis. A grande maioria das tomadas de decisões e planejamento estratégico está sendo produzidas por um novo ramo da contabilidade: a Controladoria.

\footnotetext{
${ }^{1}$ Orientanda de Trabalho de Conclusão do Curso de Bacharel em Ciências Contábeis. renata.louise.rl@ gmail.com

${ }^{2}$ Orientadora Professora Especialista do Curso de Bacharel em Ciências Contábeis. erilucia@leaosampaio.edu.br.
} 
Paralelo a este novo cenário, surge o profissional controlador ou, como é mais conhecido, Controller; para fazer a diferença no auxílio do planejamento estratégico.

Assim, este profissional ganha cada vez mais importância nas discursões de planejamento estratégico no sentido de satisfazer as exigências propostas pelos gestores, trazendo a figura do Controller uma relevância cada vez mais evidente diante do cenário econômico das empresas.

Diante do desenvolvimento da função da contabilidade, em que se tem uma ramificação ganhando maior proporção dentro das empresas, no sentido de auxiliar na tomada de decisões, em meio ao cenário econômico que o país se encontra, contribuindo para a competitividade empresarial, revolucionando os métodos de planejamento e controle estratégico, fazendo com que os gestores busquem mais conhecimento sobre o novo profissional, surge a seguinte indagação: Qual o diferencial que o Controller pode trazer de melhorias, no planejamento estratégico de uma empresa?

Este trabalho discute num primeiro momento, o conceito de contabilidade, em seguida traça um breve histórico do surgimento da Controladoria. Na sequência passa aos conceitos de função, estrutura e papel da Controladoria, finalizando com a terminologia Controller e suas atribuições na empresa.

\section{Fundamentação Teórica}

\section{A Contabilidade}

Marion (2015) tem o seu entendimento de sobre a evolução da contabilidade e como ela começou a dominar o mundo contábil, quando fala que o seu desenvolvimento originou-se nos Estados Unidos, no século $\mathrm{XX}$, com expressivas pesquisas na área para que seja possível auxiliar melhor o usuário da Contabilidade.

A contabilidade é a ciência que registra, verifica e analisa todos os fatos decorrentes da situação patrimonial da entidade, expondo através de relatórios gerenciais e demonstrações contábeis, a situação da mesma.

Da Silva (2008,) no seu conceito de contabilidade, ressalta que essa ciência nada mais é do que um estudo que trabalha em acordo com a prática de controle e de registro de atos e fatos das ciências administrativas e econômicas. 
Já no entendimento de Marion (2015), o conceito de contabilidade é voltado para a gestão. É o grande auxílio na gerencia de uma entidade. Ele que coleta os dados, faz sua mensuração, os registra em forma de relatórios, para que seus usuários tenham acesso e possam auxiliar na tomada de decisões.

Através da contabilidade é que se têm informações úteis para tomadas de decisões, permitindo o controle do patrimônio da empresa. O mercado empresarial e a ramificação de atividades empresariais crescem, diante disso nota-se uma crescente importância da Contabilidade na gestão das empresas e sua tomada de decisões, principalmente na área de controle da gestão empresarial.

\section{Histórico da Controladoria}

Segundo Schmidt (2009), a Controladoria teve sua ascensão no século XX, nas grandes corporações norte-americanas, com o intuito de controlar as transações que eram feitas entre as empresas relacionadas com essas corporações.

A partir da Revolução Industrial, houve um relevante número de empresas concorrentes, começaram a organizar-se e unir-se, formando grandes empresas, organizadas e sua estrutura com departamentos, que mesmo divididos ainda detinham de um controle altamente centralizado.

Nesta formação, foi requerido pelos acionistas e gestores um controle centralizado em relação a esses departamentos e divisões que propalavam rapidamente pelos Estados Unidos e outros países, seguindo a linha da descentralização.

Essa modernização da Contabilidade, no Brasil, teve como maior parte influenciadora os investidores de Inglaterra e Estados Unidos, que vieram contratados para elaborar e desenvolver os novos relatórios contábeis, conforme as novas regras e diretrizes, estes então foram os primeiros controllers, no país.

Surgindo com a evolução das organizações, a controladoria trouxe uma nova gestão, imposta para os usuários, neste caso os gestores das entidades, um novo formato de acompanhamento e avaliação das demonstrações.

A Revolução Industrial veio como uma alavanca para a origem da Controladoria, ligando diretamente esta aos processos evolutivos de produção e meios sociais, entre eles, o aumento das organizações, a globalização das empresas, o crescimento das relações de negócios e o aumento das fontes de capital. 
Schmidt, Santos \& Martins (2014), fazem uma abordagem resumida do impacto desses quatro fatores, fazendo com que a Controladoria surja como uma ramificação de conhecimento na área de gestão empresarial, para dar ao processo de evolução das organizações, uma resposta à forma da necessidade de propalar novos poderes e responsabilidades nas empresas; em concordância com essa deficiência, define-se então que a controladoria tenha um papel de controle contábil, nas comparações de demonstrações voltadas para o controle interno.

\section{A Controladoria}

A Controladoria é uma ferramenta além de muito importante basicamente indispensável, na gestão de empresas. Traz como missão auxiliar os gestores nas tomadas de decisões, aperfeiçoando-as, expandido suas informações com relevância e confiabilidade, na intenção de aprimoramento dos negócios da entidade.

Para Nascimento \& Reginato (2015), a Controladoria atua compreendendo as operações da empresa, coletando informações e comunicando estas aos gestores, sendo capaz de analisar as informações obtidas de diversas áreas, disponibilizando projeções baseadas em sua obtenção e análise, fornecendo-as, por fim, em tempo hábil para a tomada de decisão.

Baseando-se na visão acima, temos ainda, conforme Oliveira, Perez Jr. e Silva (2015), a Controladoria não como um órgão, mas sim como um departamento dentro da contabilidade que pode ou não ter finalidades lucrativas, e tem função de projetar, elaborar, programar e manter o sistema integrado de informações operacionais, financeiras e contábeis da entidade desejada.

Quando se trata de sua importância, Morante e Jorge (2008) explanam que, a controladoria está citada como um departamento trazido do exterior através das multifuncionais, como um órgão de suma importância no crescimento e ascensão das empresas. Figura, como um departamento para a administração das grandes organizações.

Barreto (2008, p.15), no seu entendimento mais amplo, considera que, a atuação da Controladoria não deve se restringir apenas a dirigir e acompanhar os processos do sistema contábil da entidade. Ela se expande e consequentemente se transforma em um leque de dados que auxilia os usuários da alta administração da entidade com informações relevantes para nas tomadas de decisões.

Diante disso, apresenta-se a Controladoria como uma ferramenta utilizada pelos gestores da entidade, voltada para examinar e controlar os processos, visando sempre apresentar 
a esses gestores, através de suas informações e dados o que pode vir a ser um perigo para a rentabilidade da entidade, tanto nos processos de curto como nos de longo prazo.

\section{Funções e Objetivos}

Como visto em seus conceitos, cada vez mais a Controladoria abrange campos maiores, convertendo-se em um banco de dados que oferece aos seus usuários maiores informações, que serão de grande relevância no processo de tomada de decisões.

Têm-se várias definições de funções da controladoria, em resumo pode-se dizer que são estabelecer, estruturar e conservar um plano integrado para o controle das operações; gerenciar, preparar; bem como, desenvolver os sistemas de controle quanto ao seu risco operacional, informações disponíveis e controle de negócios.

Kanitz (apud OLIVEIRA, PEREZ JR. e SILVA, 2015), no que lhe concerne, compreende que as funções da Controladoria se resumem na ordem que devem ser executadas, como sendo:

$$
\begin{aligned}
& \checkmark \text { Informação; } \\
& \checkmark \text { Motivação; } \\
& \checkmark \text { Coordenação; } \\
& \checkmark \text { Avaliação; } \\
& \checkmark \text { Planejamento e } \\
& \checkmark \text { Acompanhamento. }
\end{aligned}
$$

Fundamentalmente, o controller exerce suas funções de duas formas distintas. A primeira como um "contador geral”, na responsabilidade de gerar conteúdo de informações nos setores da entidade, que são de sua competência. Na análise de balanços, escrituração, elaboração de relatórios contábeis, relatórios gerenciais, registro de patrimônio, entre outras competências de um gerente de contabilidade, subordinado do diretor financeiro. A segunda forma está diretamente ligada à administração, a partir das informações geradas pelos setores da empresa, faz-se um "filtro" do que é mais relevante, não sendo sua função elaborá-las, garantindo aos usuários que as informações sejam tempestivas. 


\section{Estruturação da Controladoria}

A Controladoria precisa ter uma estrutura que cumpra suas funções, de acordo com as necessidades dos gestores sobre suas atividades, na supervisão das etapas do processo de gestão da empresa.

No conceito Oliveira, Perez Jr. e Silva (2015), a estruturação da Controladoria, fica dividida em dois grandes blocos, cada um com suas vastas funções; no primeiro bloco tem-se a área Contábil e fiscal: que é a área onde se encontra tudo que for exercido pela contabilidade tradicional e suas atribuições, que são as atividades de escrituração contábil e fiscal e seus relatórios; já a outra área o Planejamento e controle: fica caracterizada como a nova contabilidade, onde se enquadram as vastas atribuições da Controladoria.

Nesta estrutura, as atividades de monitoramento dos controles resultam na melhoria dos sistemas, em virtude desta melhoria haverá os gestores tendem a aumentarem seu desempenho e haverá ainda, um aumento na eficácia e eficiência das unidades, em consequência das informações em relação às deficiências das empresas se tornarem mais claras e evidentes, para que se possam tomar as devidas medidas corretivas. Ver figura 2.1:

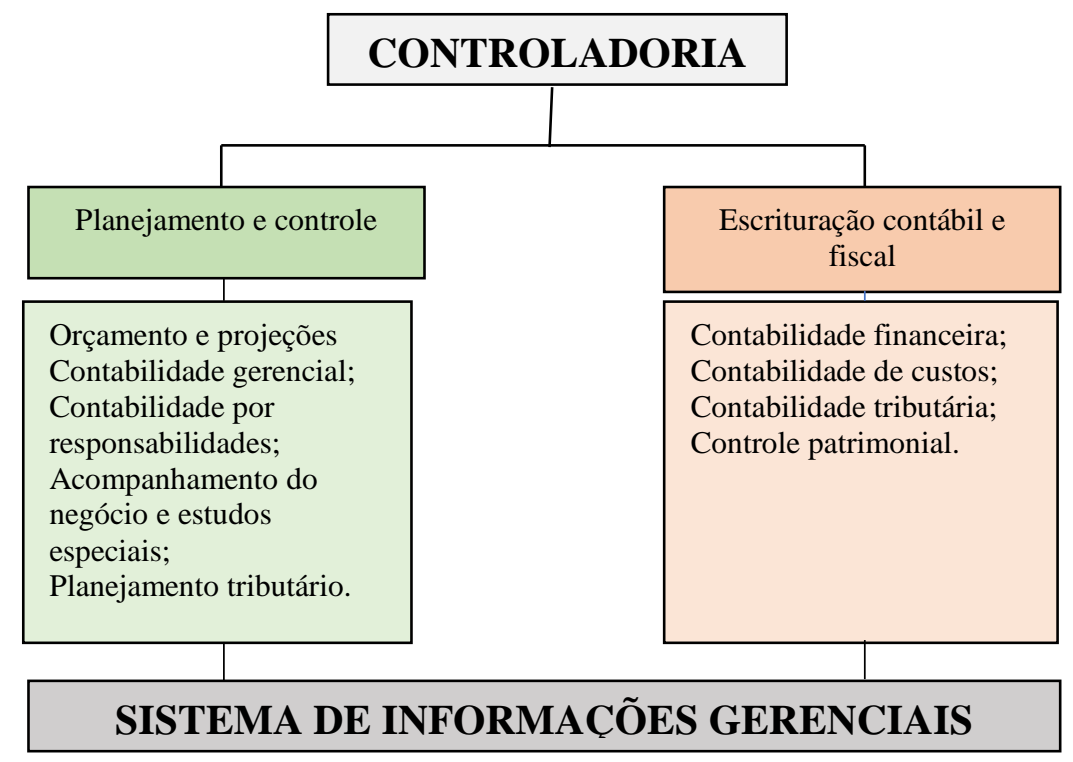

Figura 21. Estrutura da Controladoria. Oliveira, Perez Jr. \& Silva (2015).

A estrutura apresentada acima, na Figura 2, detalha-se da seguinte maneira conforme Padoveze (2016): A área contábil e fiscal tem como responsabilidade todo contexto fiscal e societário, tendo como exemplos os demonstrativos a ser publicado, controle patrimonial, de inventários e de seguros, impostos e etc. E a área de planejamento e controle está ligada a 
orçamentos, projeções e simulações, custos e contabilidade por responsabilidade, elaboração de projetos e análises de investimentos.

\section{O Controller}

“Trata-se de um profissional generalista, por reunir experiência nas áreas financeira, contábil e administrativa, e por ser também o responsável pelo planejamento de curto e longo prazo da empresa." (OLIVEIRA, PEREZ JR e SILVA, 2015, p. 27).

Como detém de propriedade de conhecimento no que se refere à gestão em relação a conhecer a entidade e seus planos, o profissional Controller, no entendimento de Padoveze (2016), exerce uma grande influência nas decisões dos gestores das entidades.

Controller como profissional tem o papel de desempenhar as funções gerenciais, econômicas e financeiras da entidade, fazendo com que sejam informações relevantes e confiáveis para os usuários e gestores.

Crepaldi (2017) tem um conceito de Controller que explana sua importância para a cúpula administrativa, nos processos de planejamento e controle, preparando os gestores a planejarem, executarem e controlarem de maneira correta as atividades da entidade, usando com eficácia e eficiência todos os dispositivos que tiver disponível, com a missão e objetivo da entidade, transportando-a ao sucesso.

O papel do controller ganha uma grande importância e relevância, não somente como o responsável pelo reporte de informações para a divisão e para a matriz, mas como responsável pela geração de informações das decisões locais dos gestores das unidades. Schmidt, Santos \& Martins (2014).

Para Da Silva (2008), um conceito de controller na sua função geral é de que ele analisa o comportamento dos custos, investimentos, despesas e receitas em diversos níveis de produção, explica as oscilações dos resultados; dessa forma, auxilia o administrador a entender melhor a rentabilidade de diversos níveis de produção.

\section{A Controladoria como Ferramenta de Gestão}

A Controladoria como ferramenta da gestão, exerce um papel funcional em todas as áreas de uma entidade. Por meio de seus relatórios auxiliando com propriedade no assunto a tomada de decisões, com segurança e confiabilidade. 
A controladoria é essencial para os processos de controle e de planejamento das organizações, segundo Oliveira (apud BARRETO, 2008) entende-se como controladoria um departamento que trabalha na elaboração e manutenção do projeto do sistema de informações da entidade.

Deste modo, é indispensável que a entidade tenha um controle eficaz e que possa ser propalado como um todo, de forma clara e objetiva, desenvolvendo o desempenho através de seu processo de gestão e o levado à eficácia organizacional.

A ascendência da Controladoria na empresa e o interesse pelo assunto podem ser explicados por Oliveira, Perez Jr. \& Silva (2015) que ressaltando a importância do controller, dizem que este novo cargo da controladoria, teve uma valorização nestes últimos anos, acarretada pela globalização e como estratégia de competitividade nas entidades.

O processo de gestão é também conhecido como decisório, e ele é motivado pela Controladoria atrás das suas ações de planejamento e controle, produzindo informações que atendam aos pedidos exigidos.

Controladoria tem como missão é aprimorar os resultados econômicos da entidade, por meio da determinação de um modelo de informações, fundamentada no modelo de gestão. O papel da Controladoria, deste modo, é auxiliar nas diversas gestões da entidade, proporcionando mensurações das alternativas econômicas, para integrar informações e reporta-las para simplificar o processo decisório.

Para Barreto (2008), os processos de controle e planejamento, são correlacionados, não se pode falar em controle sem que se tenha um planejamento executado para analisar os acontecimentos dentro da expectativa organizacional. Consequentemente, não é possível se elaborar um planejamento sem uma organização idealizada de controle para acompanhar a efetivação do que se foi idealizado.

\subsubsection{Planejamento}

O Planejamento deve ser considerado como um processo elaborado no intuito de que se alcance uma situação de longo prazo desejado, trabalhando neste processo de um modo mais eficaz com maior apoio dos gestores da entidade.

O processo de planejamento pode ser dividido em três tipos, o planejamento estratégico, o planejamento tático e o planejamento operacional, conforme mostrado a seguir, na figura 2.2: 


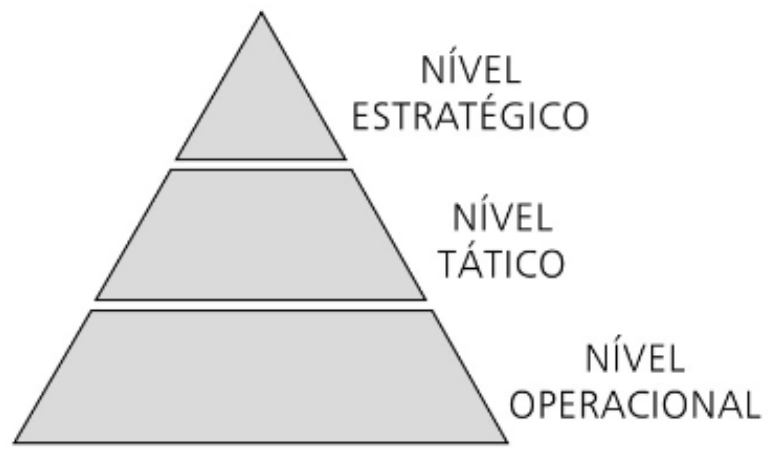

\begin{tabular}{c|c}
$\begin{array}{c}\text { Decisões } \\
\text { estratégicas }\end{array}$ & $\begin{array}{c}\text { Planejamento } \\
\text { estratégico }\end{array}$ \\
\hline $\begin{array}{c}\text { Decisões } \\
\text { táticas }\end{array}$ & $\begin{array}{c}\text { Planejamento } \\
\text { tático }\end{array}$ \\
\hline $\begin{array}{c}\text { Decisões } \\
\text { operacionais }\end{array}$ & $\begin{array}{c}\text { Planejamento } \\
\text { operacional }\end{array}$
\end{tabular}

Figura 2.2 Níveis de decisão de tipos de planejamento. Oliveira (2015)

De acordo com a figura 2.2, os tipos de planejamento de forma resumida correlacionam em níveis de decisão, como monstra pirâmide, o estratégico tem objetivos de longo prazo com estratégias e ações que afetam a empresa como um todo e o tático tem objetivos de curto prazo, com estratégias e ações que afetam somente parte da empresa (Oliveira, 2015).

Ainda no que se refere a tipos de planejamento a visão de Oliveira (2015, p.18), define os três tipos de planejamento resumidamente, da seguinte forma:

Planejamento Estratégico é onde se traça qual rumo à entidade deverá seguir; Planejamento Tático aperfeiçoa somente a área que se buscou ter um resultado deixando de lado neste momento a empresa por completo; e o Planejamento Operacional é onde, se concretiza os processos desenvolvidos e se executa os resultados obtidos.

Segundo o conceito de Mosimann (1993) planejamento é quando se determina o que de objetivos tem numa entidade e como eles serão alcançados, servindo o planejamento de elo para se conectar onde a entidade está e para onde ela quer ir.

\section{Controle}

O Controle, nada mais é do que o comparativo do que é real comparado ao que deveria ser tendo como principal finalidade, encontrar a principais divergências e suas origens para que sejam providenciadas as correções.

Schimidt e Santos (2009), no seu entendimento, conceituam a importância da função controle no processo decisório, como sendo a mais crítica para a controladoria. Nessa fase o Controller, se torna o responsável por acompanhar todos os planos e avaliações da entidade.

Um sistema de controle, segundo Anthony e Govindarajan (apud SCHIMIDT e SANTOS 2009, p.68) devem conter no mínimo quatro elementos básicos, que são eles: 
- detector ou sensor: esse componente caracteriza-se como um dispositivo de medição que reage ao aparecimento de uma situação, no processo que está sendo controlado; - avaliador: componente que determina a importância da situação que está ocorrendo. Geralmente, essa importância deverá ser avaliada por comparação com padrões ou com metas de o que deveria estar ocorrendo;

- executante: o componente executante do sistema de controle altera o comportamento do sistema quando o componente avaliador indica a necessidade de alteração. Esse dispositivo é chamado, normalmente, retroalimentação (feedback);

- rede de comunicação: componente do sistema que transmite a informação entre o detector e o avaliador, e entre o avalia- dor e o executante. Anthony e Govindarajan (apud SCHIMIDT e SANTOS 2009, p.68).

Nas empresas, controlar significa monitorar, avaliar e aperfeiçoar inúmeras atividades que ocorrem nas entidades. A função controle caracteriza-se como um mecanismo administrativo determinado pela complexidade das entidades com o propósito de obter um bom resultado. O controle compreende as atividades desenvolvidas e exigidas pelos gestores para conciliar os resultados reais com os esperados.

\section{O Planejamento Estratégico}

O planejamento estratégico é, uma responsabilidade dos níveis mais altos da entidade e diz respeito tanto à formulação de objetivos quanto à seleção dos cursos de ação - estratégias - a serem seguidos, levando em conta os ambientes externos e internos da entidade e sua evolução esperada.

Partindo desde conceito, tem-se um organograma organizacional de como se desenvolve a missão e valores estratégicos, os elementos dos objetivos e a decisão para o rumo da entidade, que pode ser visto na figura 2.3 como se segue:
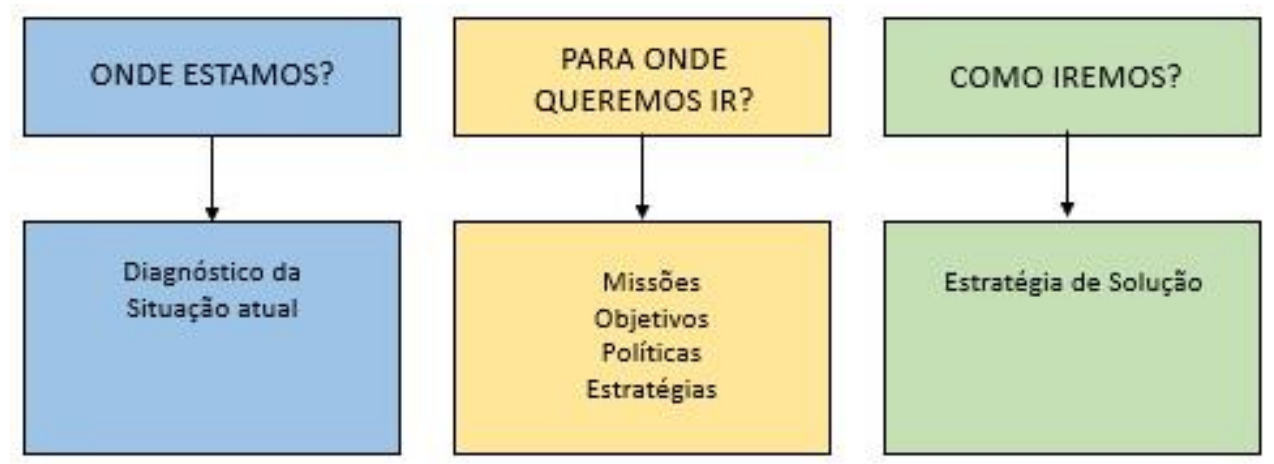

Figura 2.3 Planejamento Estratégico. Oliveira, Perez, Jr \& Silva (2015). 
Oliveira (2015, p.16), em seu entendimento de relação com os objetivos conceitua de forma resumida que, "o planejamento estratégico relaciona-se com objetivos de longo prazo e com estratégias e ações para alcançá-lós que afetam a empresa como um todo.”.

A necessidade de um planejamento é evidente que chega a ser indispensável sua utilização, é uma das atividades mais complexas e completas para se desenvolver. É de suma importância ser feito, para auxiliar antes de tomar qualquer decisão, seja ela de curto ou longo prazo; seu papel de evitar ações irregulares ajuda a reduzir os fracassos da entidade.

\section{Elaboração do Plano Estratégico}

Considerando a necessidade que as entidades possuem de terem um planejamento consistente com a missão, a controladoria deverá atuar de forma conjunta com os executivos para que no processo de construção do plano sejam consideradas as várias alternativas plausíveis disponíveis para elaboração do planejamento.

Diante desta afirmativa, os autores (SCHMIDT e DOS SANTOS, 2009, p.63), consideram os seguintes fatores, para elaboração do plano:

- os recursos disponíveis são limitados;

- existe uma incerteza sobre a capacidade operacional e sobre as intenções dos adversários;

- uma vez comprometidos os recursos, essa situação é irreversível;

- $\quad$ as ações que estão sendo planejadas serão implementadas no futuro;

- existe uma grande incerteza sobre o controle da situação futura;

- deverá ser considerado que as percepções sobre o futuro não são as mesmas para todos os envolvidos no processo;

- o sistema de planos que deve abranger o todo - para todas as atividades do negócio e para todos os períodos do planejamento - e seus relacionamentos com cada um.

Oliveira, Perez Jr e Silva (2015), elaboram alguns quesitos que devem ser levados em consideração, na estruturação dos planos estratégicos, que são as áreas, funções e hierarquias envolvidas; quem são os responsáveis pela operacionalização; quais e quantos são os dados internos e externos que deverão ser considerados relevantes.

Para se construir um plano estratégico, segundo o pensamento de SCHMIDT e DOS SANTOS, (2009), deve ser observado com cautela, como são os relacionamentos dentro da entidade, englobando todos os profissionais que nela atuam suas relações com outras entidades onde se tenham algum tipo de colaboração, como coligadas, investidas ou controladas.

Através do planejamento estratégico a entidade busca, no entendimento de Oliveira (2015, p.36): 
a) conhecer e melhor utilizar seus pontos fortes internos. Ponto forte é a diferenciação conseguida pela empresa - variável controlável - que lhe proporciona uma vantagem operacional no ambiente empresarial (onde estão os assuntos não controláveis pela empresa). b) conhecer e eliminar ou adequar seus pontos fracos internos. Ponto fraco é uma situação inadequada da empresa - variável controlável - que lhe proporciona uma desvantagem operacional no ambiente empresarial. c) conhecer e usufruir as oportunidades externas. Oportunidade é a força ambiental incontrolável pela empresa, que pode favorecer sua ação estratégica, desde que conhecida e aproveitada, satisfatoriamente, enquanto perdura. d) conhecer e evitar as ameaças externas. Ameaça é a força ambiental incontrolável pela empresa que cria obstáculos à sua ação estratégica, mas que poderá ou não ser evitada, desde que conhecida em tempo hábil. (OLIVEIRA, 2015, p.36).

Conforme os conceitos apresentados, entende-se que o planejamento estratégico não pode ser visto somente como uma afirmação das aspirações de uma entidade, pois nele incluise, o que se pode tirar de relevante das informações fornecidas para que se possa transformar o que há de pesquisa em realidade e auxiliar a entidade nas tomadas de decisões.

\section{O Controller no Planejamento Estratégico}

A tarefa primária do controller é atuar como o coordenador que monta e mantém o plano, resultando em um relatório, bem como tudo que se resulte deste, para o apoio da entidade.

Schmidt, Santos e Martins (2014), explanam o papel da controladoria na elaboração do planejamento de uma entidade, afirmando que esteja direcionado, inicialmente, no processo de elaboração do plano, é função da controladoria fazer com que o plano seja criado; no papel do controller, estes autores ainda dizem:

Ainda para Schimdt, Dos Santos e Martins (2014), o controller deverá atuar fortemente na construção do plano de ação de uma entidade, pois será seu papel contribuir para:

- determinar a missão da entidade;

- $\quad$ selecionar os objetivos em longo prazo;

- desenvolver estratégias competitivas.

O controller deverá ter um conhecimento muito vasto do mercado, ambientes externos e do produto, igualmente das influências que podem acontecer internamente nesta entidade, para que se possa participar destas ações acima descritas.

O Controller, assim, deverá ser um líder de comando principal no processo de elaboração do plano estratégico, colaborando de modo mais que direto com todos os usuários que necessitem de esclarecimentos e informes, neste primeiro momento com essas ideias iniciais. Não é a atribuição do profissional controller a aprovar como ficou o plano depois de 
finalizado, pois essa responsabilidade é do presidente e de cada executivo responsável pelas diversas áreas da entidade.

\section{Metodologia}

A metodologia tem como sua principal característica auxiliar o pesquisador no que se trata de compreensão dos termos e processos utilizados na pesquisa. Na visão de Matias-Pereira (2016, p.43), “é a lógica do procedimento científico e tem um caráter normativo, que se diferencia claramente da teoria (substantiva)".

Quanto ao método e técnica utilizada para a pesquisa, utilizou-se do método de pesquisa descritiva, como o conceito de Matias-Pereira (2016) traz, que este é um método que trabalha a descrição das características do estudo realizado, juntamente busca relacionar os fatos, onde neste trabalho foi descrito as características de controladoria e do controller, com base nas pesquisas encontradas em livros de metodologia cientifica, utilizando-se de livros, revistas e artigos, que abordam o assunto.

Segundo (Marconi e Lakatos, 2017, p. 32), “A pesquisa bibliográfica é realizada com base em fontes disponíveis, como documentos impressos, artigos científicos, livros, teses, dissertações.”.

A forma de abordagem é definida como de cunho qualitativo por procurar identificar o papel do controller nas entidades, bem como suas funções e atribuições. Segundo De Sordi (2013, p.100), “A pesquisa qualitativa emprega técnicas interpretativas para análise e compreensão de fenômenos, de natureza subjetiva".

Como já explanado acima, os métodos de utilização dispostos neste trabalho, foram de uma pesquisa bibliográfica, com metodologia descritiva, trazendo uma abordagem qualitativa, visando que se tenha uma melhor compreensão das situações expostas.

\section{Considerações Finais}

Este trabalho buscou evidenciar, a importância do profissional da Controladoria, nas entidades, e principalmente no seu planejamento estratégico. Constatou que as funções, atribuições do Controller, são muito relevantes nas tomadas de decisões. 
A função da controladoria, no suporte à entidade é de fornecer dados e informações, planejar e direcionar planos para curto e longo prazo nas entidades, afim de que sejam prevenidos erros, bem como promover a eficácia das decisões tomadas, através de suas atribuições.

A necessidade de crescimento e especialização mostrou que cada vez mais as empresas estão em busca de um profissional que abranja todo conteúdo e informação para exercer função de Controller.

O setor de Controladoria passa a ser um dos mais importantes na entidade, pois dele é que irão ser extraídas todas as informações que a empresa necessita informações estas, que são elaboradas, processadas e análises por um profissional qualificado e capacitado, o Controller.

Diante de tudo que foi exposto, conclui-se que uma empresa que adora a Controladoria no seu processo de gestão tem como benefícios a avaliação de seus resultados econômicos para que sejam atingidos os objetivos, e também assegurar a continuidade da empresa no mercado.

Com isso o objetivo deste trabalho foi além do que explano, mostrar como a Controladoria e o Controller, atuam dentro de uma entidade, sendo então a fonte principal de informações relevantes e como estas informações são repassadas e usadas pelos usuários, dentro do setor administrativo da empresa, na tomada de decisões assertivas.

\section{Referências}

BARRETO, Maria da Graça Piatá. Controladoria na gestão: a relevância dos custos da qualidade. 1 ed. São Paulo, 2008.

CREPALDI, Silvio Aparecido; CREPALDI, Guilherme Simões. Contabilidade Gerencial: teoria e prática. 8 ed. São Paulo. Atlas, 2017.

DE SORDI, José Osvaldo. Elaboração de pesquisa científica: seleção, leitura e redação. 1. ed. São Paulo: Saraiva, 2013.

FIGUEIREDO, Sandra. CAGGIANO, Paulo Cesar. Controladoria: teoria e prática. 5. ed. São Paulo: Atlas, 2017.

LAKATOS, Eva Maria. MARCONI, Marina de Andrade. Metodologia do trabalho científico: projetos de pesquisa / pesquisa bibliográfica/ teses de doutorado, dissertações de mestrado, trabalhos de conclusão de curso. 8. ed. São Paulo: Atlas, 2017.

MARION, José Carlos. Contabilidade Empresarial. 17. ed. São Paulo: Atlas, 2015.

MATIAS- PEREIRA, José. Manual de metodologia da pesquisa.4. ed. São Paulo: Atlas, 2016. 
MORANTE, Antonio Salvador; JORGE, Fauzi Timaco. Controladoria: análise financeira, planejamento e controle orçamentário. 1. Ed. São Paulo: Atlas, 2008.

MOSIMANN, Clara Pellegrinello, ALVES, Osmar de C., FISCH, Silvio. Controladoria: seu papel na administração de empresas. Florianópolis: ESAG, 1993.

NASCIMENTO, Auster Moreira; REGINATO, Luciene. Controladoria - Instrumento de apoio ao processo decisório. 2. ed. São Paulo: Atlas, 2015.

OLIVEIRA, Djalma de Pinho Rebouças de. Planejamento Estratégico: conceitos, metodologia e práticas. 33. ed. São Paulo : Atlas, 2015.

OLIVEIRA, Luis Martins de; PEREZ JR, José Hernandez; SILVA, Carlos Alberto dos Santos; Controladoria Estratégica. 11. ed. - São Paulo: Atlas, 2015.

PADOVEZE, Clóvis Luís. Controladoria Básica. 3. ed. rev. e atual. São Paulo: Cengage Learning, 2016.

SCHMIDT, Paulo; DOS SANTOS, José Luiz. Fundamentos de Controladoria. 1. ed. 2. reimpr. São Paulo: Atlas, 2009. - (Coleção resumos de contabilidade; v. 17).

SCHMIDT, Paulo; DOS SANTOS, José Luiz; MARTINS, Marco Antônio dos Santos. Manual de Controladoria. São Paulo: Atlas, 2014.

SILVA, Edson Cordeiro da. Contabilidade empresarial para gestão de negócios: guia de orientação fácil e objetivo para apoio e consulta de exectivos. São Paulo: Atlas, 2008.

Como citar este artigo (Formato ABNT):

ALVES, Renata Louise; MCÊDO, Maria Erilúcia Cruz. O Papel do Controller no Planejamento Estratégico de uma Empresa. Id on Line Rev.Mult. Psic., 2019, vol.13, n.43, p. 45-59. ISSN: 19811179.

Recebido: 13/11/2018;

Aceito: 19/11/2018 